\title{
Large cuff volumes impede posterior pharyngeal mucosal perfusion with the laryngeal tube airway
}

\author{
[Un ballonnet de grand volume gêne la perfusion de la muqueuse pharyngienne \\ postérieure réalisée avec le tube d'intubation laryngée]
}

Joseph Brimacombe MB CHB FRCA MD,${ }^{*}$ Christian Keller MD,$\dagger$ Winfried Roth MD, $\dagger$ Alex Loeckinger MD $\dagger$

Purpose: The laryngeal tube airway (LTA) is a new extraglottic airway device with a large proximal cuff that inflates in the laryngopharynx and a distal conical cuff that inflates in the hypopharynx. We determine the influence of the cuff volume and anatomic location on pharyngeal mucosal pressures for the LTA.

Methods: Fifteen fresh cadavers were studied. Microchip sensors were attached to the (anatomic location) anterior, lateral and posterior surface of the distal cuff (hypopharynx) and proximal cuff (laryngopharynx) of the size 4 LTA. Oropharyngeal leak pressure (OLP) and mucosal pressures were measured at $0-140 \mathrm{~mL}$ cuff volume in 20-mL increments. In addition, mucosal pressures for the proximal cuff were measured in three awake, topicalized volunteers.

Results: OLP and mucosal pressure at all locations increased with cuff volume (all: $P<0.01$ ). Mucosal pressures were highest posteriorly. Mucosal pressures only exceeded $35 \mathrm{~cm} \mathrm{H}_{2} \mathrm{O}$ (pharyngeal mucosal perfusion pressure) in the anterior and posterior laryngopharynx and when the cuff volume was $>80-100 \mathrm{~mL}$. Mucosal pressures were similar for cadavers and awake volunteers.

Conclusion: Mucosal pressures for the LTA increase with cuff volume, are highest posteriorly and potentially exceed mucosal perfusion pressure when cuff volume exceeds $80-100 \mathrm{~mL}$.

Objectif : Le tube d'intubation laryngé (TIL) est un nouvel appareil d'intubation extraglottique muni d'un grand ballonnet proximal qui se gonfle dans le laryngopharynx et d'un ballonnet conique distal qui se gonfle dans l'hypopharynx. Nous avons déterminé l'influence du volume du ballonnet et du site anatomique sur les pressions de la muqueuse pharyngienne avec l'utilisation du TIL.

Méthode : Nous avons étudié 15 cadavres récemment décédés. Des micropuces ont été fixées à la surface antérieure (site anatomique), latérale et postérieure du ballonnet distal (hypopharynx) et proximal (laryngopharynx) du TIL de taille 4. La pression de fuite oropharyngienne (PFO) et les pressions de la muqueuse ont été mesurées pour un volume de ballonnet de $0-140 \mathrm{~mL}$ en paliers de $20 \mathrm{~mL}$. De plus, les pressions de la muqueuse pour le ballonnet proximal ont été mesurées à l'état d'éveil chez trois volontaires sous anesthésie topique.

Résultats : Pour tous les sites anatomiques, la PFO et la pression de la muqueuse ont augmenté avec le volume du ballonnet (tous : $P<$ 0,01 ). Les pressions de la muqueuse ont été plus élevées sur la face postérieure et elles ont dépassé $35 \mathrm{~cm} \mathrm{H}_{2} \mathrm{O}$ (pression de perfusion de la muqueuse pharyngienne) seulement dans le laryngopharynx antérieur et postérieur et avec un volume de ballonnet $>80-100 \mathrm{~mL}$. Les pressions de la muqueuse ont été similaires chez les cadavres et les volontaires éveillés.

Conclusion : Avec le TIL, les pressions de la muqueuse augmentent avec le volume du ballonnet, sont plus élevées dans la partie postérieure et dépassent potentiellement la pression de perfusion de la muqueuse quand le volume du ballonnet est au-dessus de 80-100 mL.

$\mathrm{T}$ HE laryngeal tube airway (LTA; VBM Medizintechnik GmbH, Sulz, Germany), first described by Agro et al. ${ }^{1}$ in 1999, is a new extraglottic airway device for resuscitation and anesthesia. It consists of an airway tube with a large proximal cuff that inflates in the proximal pharynx to form an airtight seal and a distal conical cuff that inflates in the hypopharynx to prevent regurgitation and gastric insufflation. A single pilot balloon and inflation tubing inflate both cuffs. Early clinical studies suggest that there is a high insertion success rate, ${ }^{2}$ positive pressure ventilation is fair to excellent in $88 \%$

From the Department of Anaesthesia and Intensive Care Medicine, $†$ Leopold-Franzens University, 6020, Innsbruck, Austria and University of Queensland and James Cook University, Department of Anaesthesia and Intensive Care, ${ }^{*}$ Cairns Base Hospital, The Esplanade, Cairns 4870, Australia.

Address correspondence to: Prof J. Brimacombe, Department of Anaesthesia and Intensive Care, Cairns Base Hospital, The Esplanade, Cairns 4870, Australia. Fax: 617 40506854; E-mail: jbrimacombe@austarnet.com.au

Disclosure statement: This project was not funded. Accepted for publication April 5, 2002.

Revision accepted September 9, 2002. 
TABLE I Oropharyngeal leak pressure and mucosal pressures in the laryngopharynx (proximal cuff) and hypopharynx (distal cuff) for cadavers

\begin{tabular}{llllllll}
\hline $\begin{array}{l}\text { Cuff vol } \\
(m L)\end{array}$ & $\begin{array}{l}\text { Oropharyngeal } \\
\text { leak pressure }\end{array}$ & Anterior & $\begin{array}{l}\text { Laryngopharynx } \\
\text { Lateral }\end{array}$ & Posterior & Anterior & $\begin{array}{l}\text { Hypopharynx } \\
\text { Lateral }\end{array}$ & \begin{tabular}{l} 
Posterior \\
\hline 0
\end{tabular} \\
\hline $1.5(2,1$ to 2$)$ & $0(1,0$ to 1$)$ & $0(0,0$ to 0$)$ & $4(5,1$ to 6$)$ & $0(1,0$ to 1$)$ & $0(1,0$ to 1$)$ & $4(4,2$ to 6$)$ \\
20 & $6.0(6,4$ to 8$)$ & $2(3,0$ to 3$)$ & $1(1,0$ to 1$)$ & $8(9,4$ to 13$)$ & $1(1,0$ to 2$)$ & $1(2,1$ to 2$)$ & $5(5,2$ to 7$)$ \\
40 & $12.3(11,8$ to 16$)$ & $7(6,4$ to 11$)$ & $1(2,0$ to 2$)$ & $13(10,8$ to 19$)$ & $2(2,0$ to 3$)$ & $2(2,1$ to 4$)$ & $6(6,3$ to 10$)$ \\
60 & $23.3(13,18$ to 28$)$ & $16(10,10$ to 22$)$ & $7(8,3$ to 12$)$ & $19(13,12$ to 27$)$ & $3(4,1$ to 5$)$ & $3(3,1$ to 5$)$ & $11(7,7$ to 15$)$ \\
80 & $28.1(12,24$ to 33$)$ & $25(12,19$ to 32$)$ & $13(12,6$ to 20$)$ & $34(21,22$ to 46$)$ & $6(5,3$ to 9$)$ & $5(5,2$ to 8$)$ & $16(11,10$ to 22$)$ \\
100 & $32.2(10,29$ to 36$)$ & $36(22,24$ to 48$)$ & $16(14,9$ to 24$)$ & $45(27,30$ to 60$)$ & $9(7,5$ to 13$)$ & $8(6,4$ to 11$)$ & $20(12,14$ to 27$)$ \\
120 & $33.2(9,30$ to 36$)$ & $40(26,26$ to 54$)$ & $22(18,12$ to 32$)$ & $63(43,40$ to 87$)$ & $12(9,7$ to 17$)$ & $10(8,6$ to 14$)$ & $23(14,16$ to 31$)$ \\
140 & $33.5(8,30$ to 37$)$ & $45(34,26$ to 64$)$ & $25(26,11$ to 40$)$ & $85(60,52$ to 118$)$ & $19(17,10$ to 28$) 14(13,6$ to 21$) 27(17,18$ to 36$)$ \\
Overall & $21.3(15,19$ to 23$)$ & $21(24,17$ to 26$)$ & $11(16,8$ to 14$)$ & $34(39,27$ to 41$)$ & $6(9,5$ to 8$)$ & $5(7,4$ to 7$)$ & $14(13,12$ to 17$)$ \\
\hline
\end{tabular}

Data are mean $(\mathrm{SD}, 95 \% \mathrm{CI})$. Units are $\mathrm{cm} \mathrm{H}_{2} \mathrm{O}$.

TABLE II Intracuff and intercuff locational statistical comparisons for the laryngopharyngeal and hypopharyngeal cuff for cadavers.

\begin{tabular}{|c|c|c|c|c|c|c|c|c|c|}
\hline \multirow{3}{*}{ Cuff vol } & \multirow{2}{*}{\multicolumn{3}{|c|}{ Laryngopharyngeal Intracuff }} & \multicolumn{6}{|c|}{ Intercuff } \\
\hline & & & & I & popharyngea & & Laryng & vs hypophary & \\
\hline & & & Love os pos & & & Lovo o p oov & & & \\
\hline 0 & NS & $<0.01$ & $<0.001$ & NS & $<0.001$ & $<0.001$ & NS & NS & NS \\
\hline 20 & NS & $<0.01$ & $<0.001$ & NS & $<0.01$ & $<0.01$ & NS & NS & NS \\
\hline 40 & $<0.04$ & $<0.05$ & $<0.001$ & NS & $<0.01$ & $<0.01$ & $<0.01$ & NS & NS \\
\hline 60 & NS & NS & $<0.01$ & NS & $<0.001$ & $<0.001$ & $<0.001$ & NS & NS \\
\hline 80 & NS & NS & $<0.01$ & NS & $<0.001$ & $<0.001$ & $<0.001$ & NS & $<0.05$ \\
\hline 100 & $<0.05$ & NS & $<0.01$ & NS & $<0.01$ & $<0.001$ & $<0.001$ & NS & $<0.01$ \\
\hline 120 & NS & NS & $<0.01$ & NS & $<0.01$ & $<0.01$ & $<0.001$ & NS & $<0.01$ \\
\hline 140 & NS & $<0.05$ & $<0.001$ & NS & NS & NS & $<0.01$ & NS & $<0.001$ \\
\hline Overall & $<0.01$ & $<0.01$ & $<0.001$ & NS & $<0.001$ & $<0.001$ & $<0.001$ & $<0.01$ & $<0.001$ \\
\hline
\end{tabular}

NS = not significant

of patients, ${ }^{3}$ but spontaneous breathing has a high failure rate. ${ }^{4}$ In the following study, we determine the influence of cuff volume and anatomic location on hypopharyngeal and laryngopharyngeal mucosal pressures for the LTA.

\section{Methods}

Study 1

Research and Ethical Committee approval was obtained. All patients, or their relatives, consented to post- mortem research before using the cadavers. Fifteen fresh cadavers (6-24 hr post-mortem) were studied. Cadavers with known upper esophageal or laryngopharyngeal pathology were excluded. Mucosal pressure was measured directly using six $1.2-\mathrm{mm}$ diameter strain gauge silicone microchip sensors (Codman ${ }^{\circledR}$ MicroSensor $^{\mathrm{TM}}$, Johnson and Johnson Medical Ltd, Bracknell, UK) attached to the external surface of the distal and proximal cuff of a size 4 LTA with clear adhe- sive dressing $0.45 \mu \mathrm{m}$ thick (Tegaderm $^{\mathrm{TM}}, 3 \mathrm{M}$, Ontario, Canada), as previously described ${ }^{5,6}$ and validated. ${ }^{7}$ The sensors were attached to the following locations (corresponding mucosal areas): A, anterior proximal cuff (anterior laryngopharynx / base of tongue); B, left lateral proximal cuff (left lateral laryngopharynx); C, posterior proximal cuff (posterior laryngopharynx); D, anterior distal cuff (anterior hypopharynx); E, left lateral distal cuff (left lateral hypopharynx); and $\mathrm{F}$, posterior distal cuff (posterior hypopharynx). The sensing element of the sensor was orientated towards the mucosal surface and was accurate to $\pm 2 \%$. The position/orientation/accuracy of all the sensors were checked over the entire inflation range in vitro before and after use in each cadaver. ${ }^{5,6}$

The LTA was inserted into the cadaver using laryngoscope-guidance to allow the distal cuff to be placed exactly in the hypopharynx. Oropharyngeal leak pressure, in-cadaver intracuff pressures and directly mea- 
TABLE III In vivo intracuff pressures and laryngopharyngeal mucosal pressures for awake volunteers

\begin{tabular}{lllll}
\hline Cuff vol $(\mathrm{mL})$ & In vivo & Anterior & Lateral & Posterior \\
\hline 0 & -30.0 & $0(0$ to 0$)$ & $0(0$ to 0$)$ & $8(2$ to 19$)$ \\
20 & $8(3$ to 17$)$ & $0(0$ to 0$)$ & $6(0$ to 14$)$ & $13(5$ to 18$)$ \\
40 & $29(9$ to 45$)$ & $9(6$ to 16$)$ & $11(0$ to 22$)$ & $16(8$ to 24$)$ \\
60 & $43(26$ to 70$)$ & $15(4$ to 24$)$ & $16(2$ to 29$)$ & $28(15$ to 58$)$ \\
80 & $70(55$ to 93$)$ & $30(10$ to 45$)$ & $21(13$ to 32$)$ & $37(26$ to 60$)$ \\
100 & $124(97$ to 158$)$ & $32(16$ to 54$)$ & $25(15$ to 46$)$ & $68(22$ to 78$)$ \\
120 & $156(120$ tol $)$ & $44(19$ to 66$)$ & $32(17$ to 60$)$ & $102(70$ to 130$)$ \\
140 & $190(168$ to 210$)$ & $47(21$ to 63$)$ & $17(0$ to 60$)$ & $40(2$ to 130$)$ \\
Overall & $74(-30$ to 210$)$ & $22(0$ to 66$)$ & &
\end{tabular}

Data are mean (range). Units are $\mathrm{cm}_{2} \mathrm{O}$.

sured mucosal pressures were measured at $0-140 \mathrm{~mL}$ cuff volume in $20-\mathrm{mL}$ increments. Oropharyngeal leak pressure was determined by closing the expiratory valve of the circle system at a fixed gas flow of $3 \mathrm{~L} \cdot \mathrm{min}^{-1}$ until the airway pressure reached equilibrium. ${ }^{8}$

\section{Study 2}

With Research and Ethics Committee approval and written, informed consent, we studied laryngopharyngeal mucosal pressures in three healthy, fasted $(>6 \mathrm{hr})$ nonpaid subjects (ASA class I). Subjects were studied in the supine position with the occiput on a firm pillow $5-\mathrm{cm}$ in height. The airway was anesthetized with ten puffs of $1 \%$ lidocaine spray and a size 4 LTA with pressure probes attached was inserted blindly and pharyngeal pressures from the anterior, lateral and posterior proximal cuff recorded over the inflation range 0-140 mL, as above. Mucosal pressure data were not collected during swallowing or airway reflex activation. The next day, volunteers were asked about symptoms of airway morbidity.

\section{Statistics}

The distribution of data was determined using Kolmogorov-Smirnov analysis. ${ }^{9}$ Statistical analysis was with paired $\mathrm{t}$ test (normally distributed data), Friedman's two-way analysis of variance (non-normally distributed data) and one-way analysis of variance with post-hoc Bonferroni test. Significance was taken as $P<0.05$. Statistical analysis was performed on an IBM computer using SYSTAT version 7.0.

\section{Results}

Study 1

The mean (range) age, height and weight was 78 (57-88) yr, $163(145-188) \mathrm{cm}$ and $61(42-88) \mathrm{kg}$ respectively. The male:female ratio was $6: 9$. Hypopharyngeal placement of the distal cuff was achieved in 15/15 at the first attempt. Oropharyngeal leak pressure and mucosal pressures for the distal cuff in the hypopharynx and for the proximal cuff in the laryngopharynx are presented in Table I. There was a significant increase in mucosal pressure in the esophagus and pharynx at all locations with increasing cuff volume (all: $P<0.001)$. Mucosal pressures in the hypopharynx were higher in the posterior compared with the anterior and lateral locations, but were similar for the anterior and lateral locations (Table II). Mucosal pressures in the laryngopharynx were higher in the posterior compared with the anterior and lateral locations, and were higher in the anterior compared with the lateral locations (Table II). There was a significant increase in directly measured mucosal pressure with increasing cuff volume.

\section{Study 2}

The mean (range) age, height and weight for awake volunteers was $32(26-41) \mathrm{yr}, 174(158-193) \mathrm{cm}$ and 71 (49-90) kg respectively. The male:female ratio was $2: 1$. The LTA was successfully inserted at the first attempt in all volunteers. Mucosal pressures over the range of cuff volumes are presented in Table III. There were no significant differences in mucosal pressures between cadavers and awake volunteers over the inflation range. Two volunteers complained of sore throat and one volunteer of dysphagia the next day.

\section{Discussion}

We found that laryngopharyngeal and hypopharyngeal mucosal pressures with the LTA increase with cuff volume. Similar results have been obtained for the laryngeal mask airway ${ }^{10}$ and cuffed oropharyngeal airway ${ }^{11}$ in the laryngopharynx and for the laryngeal mask airway in the hypopharynx. ${ }^{10}$ We found that laryngopharyngeal and hypopharyngeal mucosal pressures were highest posteriorly. This is thought to be because the posterior surface is adjacent to rigid anatomic structures 
(vertebral bodies) whereas the anterolateral surface is adjacent to compliant anatomic structures (epiglottis, tongue and pharyngeal muscles).

Pharyngeal mucosal perfusion is progressively reduced when mucosal pressures exceed $34 \mathrm{~cm} \mathrm{H}_{2} \mathrm{O} .{ }^{12}$ Our data suggest that perfusion may be impaired in the anterior and posterior laryngopharynx with the LTA when the cuff volume exceeds $100 \mathrm{~mL}$ and $80 \mathrm{~mL}$ respectively, but perfusion of the lateral laryngopharynx and hypopharynx is unimpaired. These volumes exceed the minimal volume required to obtain an oropharyngeal leak pressure of $30-\mathrm{cm} \mathrm{H}_{2} \mathrm{O}$. We found that two out of three volunteers complained of sore throat and one out of three complained of dysphagia the day after insertion. We speculate that the high pressures exerted against the laryngopharynx at high cuff volumes will contribute to airway morbidity associated with the LTA. Reducing cuff volumes to the minimum required to form an effective seal should minimize the risk of these problems occurring.

Whilst our cadaveric findings should be interpreted cautiously, we consider them applicable to the anesthetized patient for several reasons. First, we found that pharyngeal mucosal pressures were similar for cadavers and awake volunteers. Second, there is evidence that pharyngeal compliance is similar in fresh cadavers and paralyzed anesthetized patients. ${ }^{13}$ Third, our data for cadaveric laryngopharyngeal mucosal pressures closely match those of two previous studies of the cuffed oropharyngeal airway in paralyzed anesthetized patients. ${ }^{11,12}$ Fourth, cadavers have been used to determine the risk of esophageal rupture, ${ }^{14}$ liquid flow between the esophagus and pharynx, ${ }^{15}$ pharyngeal and tracheal mucosal pressure ${ }^{16}$ and cervical motion studies. ${ }^{17}$ Our study was conducted in cadavers and awake volunteers since we considered it unethical to inflate the LTA to the maximum recommended volumes in patients due to the potential for trauma.

We conclude that mucosal pressures for the LTA increase with cuff volume, are highest posteriorly and potentially exceed mucosal perfusion pressure when cuff volume exceeds $80-100 \mathrm{~mL}$.

\section{References}

1 Agro F, Cataldo R, Alfano A, Galli B. A new prototype for airway management in an emergency: the Laryngeal Tube. Resuscitation 1999; 41: 284-6.

2 Dorges V, Ocker H, Wenzel V, Schmucker P. The laryngeal tube: a new simple airway device. Anesth Analg 2000; 90: 1220-2.

3 Asai T, Murao K, Shingu K. Efficacy of the laryngeal tube during intermittent positive-pressure ventilation. Anaesthesia 2000; 55: 1099-1102.
4 Miller DM, Youkhana I, Pearce AC. The laryngeal mask and VBM laryngeal tube compared during spontanoeus ventilation. A pilot study. Eur J Anaesthesiol 2001; 18: 593-8.

5 Brimacombe J, Keller C. Laryngeal mask airway size selection in males and females: ease of insertion, oropharyngeal leak pressure, pharyngeal mucosal pressures and anatomical position. Br J Anaesth 1999; 82 : 703-7.

6 Brimacombe J, Keller C, Giampalmo M, Sparr HJ, Berry $A$. Direct measurement of mucosal pressures exerted by cuff and non-cuff portions of tracheal tubes with different cuff volumes and head and neck positions. Br J Anaesth 1999; 82: 708-11.

7 Brimacombe J, Keller C. Pharyngeal mucosa pressures (Letter). Anesthesiology 2000; 92: 620-1.

8 Keller C, Brimacombe JR, Keller K, Morris R. A comparison of four methods for assessing airway sealing pressure with the laryngeal mask airway in adult patients. Br J Anaesth 1999; 82: 286-7.

9 Sachs L. Der kolmogoroff-smirnov-test fuer die guete der anpassung. In: Sachs L (Ed.). Angewandte Statistik (German). Berlin: Springer Verlag, 1992: 426-30.

10 Brimacombe J, Keller C. A comparison of pharyngeal mucosal pressure and airway sealing pressure with the laryngeal mask airway in anesthetized adult patients. Anesth Analg 1998; 87: 1379-82.

11 Keller C, Brimacombe J. Mucosal pressures from the cuffed oropharyngeal airway vs the laryngeal mask airway. Br J Anaesth 1999; 82: 922-4.

12 Brimacombe J, Keller C, Puhringer F. Pharyngeal mucosal pressure and perfusion. A fiberoptic evaluation of the posterior pharynx in anesthetized adult patients with a modified cuffed oropharyngeal airway.

Anesthesiology 1999; 91: 1661-5.

13 Brimacombe JR, Keller C, Gunkel AR, Pubringer F. The influence of the tonsillar gag on efficacy of seal, anatomic position, airway patency and airway protection with the flexible laryngeal mask airway: a randomized, crossover study of fresh, adult cadavers. Anesth Analg 1999; 89: 181-6.

14 Vanner RG, Pryle BJ. Regurgitation and oesophageal rupture with cricoid pressure: a cadaver study. Anaesthesia 1992; 47: 732-5.

15 Brimacombe J, Keller C. Water flow between the upper esophagus and pharynx for the LMA and COPA in fresh cadavers. Can J Anesth 1999; 46: 1064-6.

16 Dobrin P, Canfield T. Cuffed endotracheal tubes: mucosal pressures and tracheal wall blood flow. Am J Surg 1977; 133: 562-8.

17 Lennarson PJ, Smith D, Todd MM, et al. Segmental cervical spine motion during orotracheal intubation of the intact and injured spine with and without external stabilization. J Neurosurg 2000; 92: 201-6. 